\title{
Higher education scholars' participation and practices on Twitter
}

\section{G. Veletsianos}

University of Texas at Austin - Instructional Technology, Austin, Texas, USA

\begin{abstract}
Scholars participate in online social networks for professional purposes. In such networks, learning takes the form of participation and identity formation through engagement in and contribution to networked practices. While current literature describes the possible benefits of online participation, empirical research on scholars' use of online social networks in the educational technology literature is negligible. The purpose of this paper is to understand scholars' naturalistic practices in social networks in general, and on Twitter in particular. Tweets from 45 scholars were analysed qualitatively to arrive at dominant themes describing online social network practice. Findings indicate that scholars participating on Twitter (1) shared information, resources, and media relating to their professional practice; (2) shared information about their classroom and their students; (3) requested assistance from and offered suggestions to others; (4) engaged in social commentary; (5) engaged in digital identity and impression management; (6) sought to network and make connections with others; and (7) highlighted their participation in online networks other than Twitter. These findings assist the field in understanding the emerging practice of scholarly participation in online networks.
\end{abstract}

Keywords

Online participation; online social networks; digital scholarship; social networking sites; Twitter; higher education.

The prevalence of online social networking and participation in online spaces has attracted the attention of researchers who have sought to understand the use of such networks for learning and educational purposes. Research on social network sites (SNSs) in the educational technology literature has investigated a wide range of topics including youth's online practices (Ito et al. 2009), the relationship between online social networks and educational outcomes (Kirschner \& Karpinski 2010; Junco et al. 2011), and students' attitudes towards online social networks (Hew 2011). Recent literature has also proposed that participatory Internet technologies may offer expanded opportunities to scholars for professional endeavours, transforming the ways

Accepted: 5 August 2011

Correspondence: George Veletsianos, University of Texas at Austin Instructional Technology, 244L Sanchez Building 1, University Station D5700, Austin, Texas 78712, USA. Email: veletsianos@gmail.com academics engage in teaching and research (Greenhow et al. 2009; Katz 2010). For example, scholars can maintain ongoing interactions with geographically dispersed colleagues, post drafts of their manuscripts online and invite colleagues to comment and critique their work prior to formal publication (e.g. Conole 2011), or they can work with others on a large scale, capitalizing on a group's collective intelligence and division of labour, to solve hard problems [e.g. see Gowers \& Nielsen (2009) and Gowers success in engaging numerous individuals in finding a proof for a complex mathematical problem]. Yet, the topic of scholars' participation in online spaces has received scant empirical attention in the educational technology literature (Greenhow 2009). Understanding scholars' use of online social networks will enable us to investigate scholars' values, the relationship between participatory technologies and scholarly practice, ${ }^{1}$ the implications of online social networking for scholarship 
and education, and the extent to which academia may or may not be changing as a result of scholars' ability to connect digitally with each other.

The purpose of this paper, therefore, is to fill this gap in the literature by investigating scholars' practices in networked spaces. To investigate this topic, I examine scholars' naturalistic practices on Twitter, through a qualitative lens. I focus on scholars' practices on Twitter because the application appears to be popular among higher education faculty [e.g. a recent survey of higher education professionals showed that more than $35 \%$ of 1372 respondents use Twitter (Faculty Focus 2010)], and has been appropriated and repurposed for educational and scholarly endeavours. I first present a review of related literature and discuss what this literature means for scholars' online participation. Next, I present the study's research questions and methods. Finally, I discuss the results, interpretations, and implications of the study.

\section{Literature review}

The Web has undergone drastic changes in the last 10 years as it transitioned from a location that users would visit to retrieve information posted by a small group of content experts (Web 1.0), to a 'read-and-write' platform (Web 2.0) that enables content contribution/ sharing/remixing and participatory practices (Greenhow et al. 2009). Web 2.0 technologies include social networks (e.g. Facebook), media-sharing sites (e.g. YouTube), blogging platforms (e.g. Wordpress), microblogging platforms (e.g. Jaiku), content aggregators (e.g. Google Reader), social bookmarking sites (e.g. Diigo), and other emerging forms of participatory media (e.g. Question-answer services such as Quora). In this paper, I focus on Twitter, a Web 2.0 technology that I consider to be a microblogging service with social network features. Others consider Twitter to be a microblogging platform (e.g. Java et al. 2007; Ebner et al.2010). A microblog is a service that allows users to write brief text updates (140 characters in the case of Twitter) from mobile devices and personal computers and publish them on the Web (Oulasvirta et al. 2009). Twitter's social network features arise from users' capabilities to articulate their connections with others, and are in alignment with the definition of SNSs posed by boyd and Ellison (2007, p. 211): 'web-based services that allow individuals to (1) construct a public or semi- public profile within a bounded system, (2) articulate a list of other users with whom they share a connection, and (3) view and traverse their list of connections and those made by others within the system'. Twitter's network features can also be explained by reference to Dron and Anderson (2009) who have categorized online social organizations and have distinguished between groups, networks, and collectives. According to these authors, a network is a fluid and generative entity in which participation consists of distributed individuals connected in loose and strong ties, membership is mostly unrestricted, and participants may know some but not all members of the network. Individuals participating on Twitter, therefore, create their own individual and unique networks in which learning occurs. In this paper, learning is considered to be a situated activity and takes the form of participation in a network of individuals who pursue scholarly endeavours (cf. Lave \& Wenger 1991; Wenger 1998). Rather than viewing learning as acquisition of a body of knowledge, this perspective views learning as the process of becoming a participant in the socio-cultural practice of scholarship through social interaction, development of shared (or non-shared) practices, and activities within sociocultural environments. In this context, Twitter serves as an emerging and evolving network of scholar-learners where scholarly practices may be created, refined, performed, shared, discussed, and negotiated.

The activities of young people on SNS are one of the focal points of current research (Ito et al. 2009; Greenhow 2011). Such research has found that SNSs are largely used for personal rather than educational reasons (Luckin et al. 2009; Selwyn 2009). For instance, prior research has found that college students' use of Facebook is positively related to the creation/ maintenance of social capital and the preservation or reinforcement of offline relationships (Ellison et al. 2007). Valenzuela et al. (2009) report similar findings, showing positive relationships between students' life satisfaction, social trust, civic and political participation, and intensity of Facebook use and Facebook Group use. What might explain these relationships? In comparing SNS users and non-users, Tufekci (2008) found that the former (1) exhibit a more positive disposition towards social grooming ('gossip, small-talk and generalized, non-functional people-curiosity'), and (2) are heavier users of the 'expressive Internet', than non-users. Tufekci (p. 578) defines the expressive 
Internet as that which allows users 'to perform and realize social interactions, self-presentation, public performance, social capital management, social monitoring, and the production, maintenance and furthering of social ties' and differs from the 'instrumental Internet' in that the latter refers to 'information seeking, knowledge gathering and commercial transactions on the Internet, and non-social communication involved in such trans- actions'. White et al. (2009) observe distinctive uses of the Internet, but focus on viewing Internet users on a continuum ranging from digital visitors to digital residents. Digital visitors are those users who visit the Internet for a specific purpose (e.g. to purchase an airline ticket or to follow their favourite soccer team), while digital residents are those users who live part of their life online and use this medium to cultivate their identities and relationships. In other words, digital visitors participate in the instrumental Internet, while digital residents, in addition to using the Internet as an information and knowledge source, enact practices associated with the expressive Internet.

The literature also presents evidence for learners using online social networks to 'fulfill essential social learning functions...[including] peer support from current and former classmates, and targeted help with school-related tasks' (Greenhow \& Robelia 2009, p. 1153), as well as to engage in identity work and formation, development of technological fluencies (such as video creation), and new literacy practices (Greenhow 2011). On the other hand, Kirschner and Karpinski (2010) show that Facebook users reported having lower mean grade point averages (GPAs) and spending fewer hours per week studying than non-users. The authors suggest that the reason for this correlation may be due to students simultaneously attending to two cognitive processes (e.g. Facebook browsing while studying), and thereby being unable to invest all necessary cognitive resources to one task. Pasek et al. (2009), however, show that this correlation may be an anomaly: Using three different data sets, they were unable to find any significant relationships between Facebook use and GPA. On the other hand, Junco et al. (2011) report that in an experiment where one experimental group used Twitter and one did not, the Twitter-using group showed higher semester GPA and a significantly higher increase in engagement than the control group. It is important to note that these findings may not be fully attributable to Twitter per se (e.g. pedagogy might have played a pivotal role). Nonetheless, the fact that Twitter was appropriated and used to examine whether it furthers educational outcomes reveals the interest that exists in the field with regard to experimenting with online social networks. Although empirical evidence on the applications of SNS in educational contexts is scant (boyd \& Ellison 2007; Greenhow et al. 2009; Greenhow 2011), emerging research in the area is examining the potential and intricacies of SNS use for education [e.g. see Greenhow (2011) and Hew (2011) for a review of research on the topic].

While youth have attracted great interest in SNS research, the implications of social networks for higher education faculty who may participate in SNS for scholarly purposes have remained unexplored. Importantly, while SNSs have shown potential to transform numerous facets of learning, teaching, and research (Greenhow et al. 2009; Oblinger 2010), these opportunities cannot be realized without a deep understanding of how scholars participate in and experience social networks (Veletsianos \& Kimmons 2011b), especially because higher education faculty frequently appropriate technologies not originally designed for their profession (e.g. Twitter) and repurpose them to fit scholarly objectives (Hemmi et al. 2009; Veletsianos 2010). Yet, research on the use of social networks by scholars is negligible (Greenhow 2009; Veletsianos \& Kimmons 2011a; Veletsianos \& Kimmons 2011b), and only recently have studies discussed faculty's use of SNS for professional non-instructional purposes. For example, in a survey of 1921 faculty members, Moran et al. (2011, p. 9) found that about $60 \%$ of faculty 'report at least monthly use of at least one social media site'. On the instructional side, adoption of social networks among scholars is limited. For instance, Ajjan and Hartshorne (2008) found that $74 \%$ of faculty studied did not plan on using social networking tools for instruction; Coddington (2010) found that social media use in higher education instruction is limited, as out of approximately 4600 faculty surveyed, $79 \%$ never used collaborative editing software (e.g. wikis) and $84 \%$ never used blogs in their teaching; and Roblyer et al. (2010) argued that higher education faculty may be more inclined to use "traditional' technologies, such as e-mail. Ajjan and Hartshorne argue that the reason SNS use for instructional purposes is rejected may be because SNSs are incompatible with the way that higher education is generally 
organized and delivered. In other words, there are structural and philosophical differences between how Web 2.0 tools envision relationships between participants and how higher education institutions envision relationships between faculty and students. For instance, while SNS may value diversity of opinion and a democratic participatory process, the higher education classroom might value the voice of a single expert (i.e. the faculty member). This explanation supports a related finding by Coddington who discovered that, in contrast to low social media use, $72 \%$ of faculty members use course management systems (e.g. Blackboard), which, generally, but not always, support instructor-centric learning environments (Veletsianos \& Navarrete 2011).

Nevertheless, academics participate in online spaces other than SNS, such as blogs and discussion forums. Meyer (2010) and Meyer and McNeal (2011) for instance studied anonymous academics' contributions to The Chronicle of Higher Education forums. In the former study, it was discovered that contributors mostly posted personal perspectives, and chose to use formal writing. In the latter study, the authors found that the majority of the discussions involved faculty's personal and professional interests with the majority of the discussions lasting less than 1 month. The authors also found evidence of discussion 'hijacking' and rude commentary, which is not an unusual phenomenon in online discussions, especially given the anonymous nature of the contributions (cf. Suler 2004).

Even though academics also blog anonymously or under a pseudonym, often as a way to engage in critical discussions of academic life (Walker 2006), numerous academic blogs identify with their authors. In explaining their motivations for blogging, scholars report that blogging provides them with a new medium to explore scholarly ideas and enables them to re-envision their identity as public intellectuals (Kirkup 2010). Similarly, Kjellberg (2010) found that researchers blog because they want to share their knowledge, connect with other researchers, and reach multiple audiences. Martindale and Wiley (2005) support Kjellberg's findings as they report that their blogging is also intended for multiple audiences including co-located and distributed students, friends, co-workers, and colleagues.

Although research on Twitter specifically is at its early stages, a number of studies may help us understand the activities of scholars on this platform. For instance, Java et al. (2007) conducted one of the first content analyses of Twitter updates and found that user intentions include daily chatter, conversations, information and link sharing, and news reporting, while Crawford (2009) characterized Twitter as consisting of 'a stream of multilayered information, often leaping from news updates to a message from a friend experiencing a stressful situation, to information about what a stranger had for lunch, all in the space of seconds' (p. 529). Within this environment, recent evidence suggests that users may have multiple networks: one that consists of all their followers and followees, and another that consists of their most intimate connections (Huberman et al. 2009). In extending these findings to educational settings, Ebner et al. (2010) noted that instructors and students can use Twitter to ask questions, give opinions, exchange ideas, share resources, and reflect, while Dunlap and Lowenthal (2009) noted that introducing their students to Twitter enabled them to engage with virtual communities and (1) interact with other professionals, and (2) gain professional exposure.

The research identified above suggests that scholars participate in social media for professional purposes but do not necessarily use them extensively for instructional purposes. What is absent from this research is an understanding of scholars' practices in social networks. While we can draw inferences on what scholars may be doing on Twitter, we currently have no empirical evidence of their activities. What do scholars do in social networks and what do their naturalistic practices reveal about scholarly practice? While selfreported accounts of academics' motivations are important in understanding the rationale of and perceived benefits to participation, an examination of in situ practices will yield further knowledge on scholarly activities online.

\section{Research questions}

The purpose of this paper is to understand scholars' practices in online spaces in general, and on the Twitter network in particular. The research questions of interest are:

- What kinds of activities do scholars engage with on the Twitter network?

- What kinds of scholarship-oriented (teachingoriented and research-oriented) practices emerge from an analysis of scholars' Twitter postings? 


\section{Method}

\section{Participants}

The participants were Twitter-using scholars whose professional responsibilities included both research and teaching duties. These individuals were selected based on the following inclusion criteria:

1 They hold a PhD.

2 Are employed by a higher education institution at a teaching and/or research role.

3 Have a public Twitter profile.

4 Are active Twitter users [defined as those who post at least once per week for the duration of a particular week (cf. Java et al. 2007)].

5 Their Twitter network during the data collection period consisted of more than 2000 followers.

The intention was to explore potentially diverse activities through a group of individuals who have already participated and experimented with Twitter. By limiting the sample to individuals with more than 2000 followers, it was hoped that the sample would be reduced to a manageable size without compromising findings. Nevertheless, this also means that the sample is limited to early adopters with a relatively large following, whose Twitter use and participation may not be representative of the 'average' Twitter-using scholar.

To select the individuals whose tweets would comprise the corpus for this study, a five-stage approach was followed. First, four individuals who were known to meet the inclusion criteria were included in the sample (convenience sampling). Thereafter, a chain referral sampling (or snowball sampling) procedure was used to identify individuals who fit the inclusion criteria. Specifically, all of the original four participants' followers were examined to search for additional individuals that fit the inclusion criteria. Next all their followers were searched, and, finally, all their followers' followers. In total, 428237 profiles were browsed to identify individuals that fit the inclusion criteria. The final sample consisted of 46 individuals. One individual was removed from the sample because he was the only individual who had not contributed an update for more than 6 months and was therefore perceived by the researcher to have ceased his/her participation on Twitter (i.e. did not fit inclusion criterion \#4). The final
Table 1. Participants' academic disciplines.

\begin{tabular}{lc} 
Academic discipline & No. \\
\hline $\begin{array}{l}\text { Social sciences (Anthropology, Education, } \\
\quad \text { Psychology, Political science, Area Studies) }\end{array}$ & 24 \\
$\begin{array}{l}\text { Applied sciences (Communication, Journalism, } \\
\quad \text { Marketing, Media Studies, Business) }\end{array}$ & 22 \\
Humanities (English, History, Law) & 4 \\
Formal sciences (Mathematics) & 1 \\
\hline
\end{tabular}

Note: The number of disciplines exceeds the number of participants because six participants held appointments at two academic departments.

sample consisted of 45 participants ( 38 men, 7 women) from multiple academic disciplines (Table 1):

According to the 2010 High Impact Universities Research Performance Index (RPI), ${ }^{2} 28$ of these participants $(62.2 \%)$ were employed by the top 500 universities worldwide as ranked by the RPI (27 in North America, and one in Europe). U.S. institutions employed 35 participants, with 28 of those being employed by U.S. universities classified as very high research activity status (18) or high research activity status (10) by the Carnegie Classification of Institutions of Higher Education (a framework for categorizing U.S. institutions).

The most frequently listed user location was the U.S.A. (32), followed by Canada (6), U.K. (2), Spain (2), and Portugal (1). Two individuals did not list their location. At the time of data collection, the leastfollowed participant had 2133 followers. The most followed participant had 89039 followers. On average, participants followed 3850 individuals [standard deviation (SD) 11653 ] and were followed by 9071 others (SD 16791$)$.

\section{Data sources}

The data corpus consisted of the latest 100 tweets from each identified participant, yielding 4500 tweets in total. All data were collected on a single day, although participants had posted these tweets over the duration of a 9-month period with posting frequency varying between participants. Approximately $72.7 \%$ of tweets were posted in the month during which data were collected, and about 15.3 and $4.8 \%$ of the data were posted in the 2 months preceding the data collection month, respectively. Four participants wrote tweets in 
Spanish, Portuguese, and French. These tweets were translated into English and included in the sample. At the time of data collection, it was unclear whether 100 tweets from each individual would suffice in answering the research questions. Nevertheless, during the data analysis phase, it became evident that the amount of data collected was sufficient to describe scholars' practice because data analysis quickly reached the point of data saturation (see below).

\section{Data collection}

The data were collected using a combination of methods: The first four users were discovered manually as described above. Thereafter, the Twitter Application Programming Interface (API) was used to retrieve lists of user followers and follower counts, thus discovering all of their followers with 2000 followers or more. Once those individuals were identified, researchers manually examined each user to identify whether he or she fit all the rest of the inclusion criteria. This process (discovering participants through use of the Twitter API and manually examining whether they fit all the inclusion criteria) was repeated two more times on newly identified participants. Once all participants were identified, their latest 100 tweets were downloaded through http:// www.searchtastic.com, which used to be a freely available service that allowed one to download a specific user's public Twitter updates.

\section{Data analysis}

The constant comparative method (Glaser \& Strauss 1967) was used to analyse the content contained in scholars' tweets, arriving at salient categories and data patterns. While both the literature and the researchers' prior experience suggested potential practices, a priori codes were avoided because Strauss and Corbin (1998) suggest these may obstruct analysis and expansion of new ideas. For this reason, when analysing data, researchers examined the topic as outside observers in a process that approximated phenomenological bracketing (Giorgi 1997), consciously containing their preconceptions and pre-understandings of the activity. Three researchers independently read and analysed the data so as to (1) note emerging patterns and (2) gain an understanding of scholars' practices. The researchers then met nine times to discuss identified categories across tweets, compare notes, and collaboratively analyse data in search of common meanings. The patterns discovered were compiled and reanalysed in order to confirm and disconfirm themes across participants. Analysis across and between the data continued until no more patterns could be identified and researchers felt that the data had been saturated. Once these patterns were identified, they were grouped into themes.

\section{Rigor}

The following strategies were employed to enhance this study's rigor and trustworthiness:

- Multiple researchers analysed the data independently as a check on individual biases.

- Intercoder reliability. Once the three researchers created the themes, a description of each one along with a 20\% random sample of the dataset was given to a fourth researcher who was asked to investigate whether any additional themes could be derived from the data. The fourth researcher analysed the data independently and did not discover any additional themes. Intercoder reliability was calculated at $72.6 \%$. Multiple codes applied to tweets might have been a contributing factor to the low score presented here. This researcher then met with the study's author to discuss the themes and the data. Coding disagreements were discussed until researchers reached consensus, and it was agreed that no more thematic categories could be identified.

- Thick descriptions. In the results presented below, a conscious effort is made to provide enough information and description of tweeting practices so that readers are able to evaluate the extent to which the results are applicable to other populations and 'determine how closely their situations match the research situation, and hence, whether findings can be transferred' (Merriam 1995, p. 58).

\section{Findings}

Qualitative data analysis revealed seven themes relating to scholarly practice online. These are described below using illustrative tweets. Tweets were edited to maintain participant anonymity. Additionally, hyperlinks were replaced by the term [URL] and course/conference/ 
Table 2. Scholar's Twitter practices and activities.

\begin{tabular}{|c|c|c|}
\hline Theme & Theme description & Example of tweet \\
\hline $\begin{array}{l}\text { Information, resource, and } \\
\text { media sharing }\end{array}$ & $\begin{array}{l}\text { Sharing information, media, and other resources } \\
\text { related to their profession }\end{array}$ & $\begin{array}{l}\text { [Speaker] is discussing education } \\
\text { and technology at [institution } \\
\text { name]: [URL] }\end{array}$ \\
\hline $\begin{array}{l}\text { Expanding learning } \\
\text { opportunities beyond the } \\
\text { confines of the classroom }\end{array}$ & $\begin{array}{l}\text { Making classroom activities/information available to } \\
\text { others and providing opportunities for students to } \\
\text { interact with individuals outside of the classroom }\end{array}$ & $\begin{array}{l}\text { My students co-authored this } \\
\text { remarkable article: [URL] }\end{array}$ \\
\hline $\begin{array}{l}\text { Requesting assistance and } \\
\text { offering suggestions }\end{array}$ & Asking for and providing assistance to others & $\begin{array}{l}\text { @user: Here is an example [URL] } \\
\text { @user. I can also send my course } \\
\text { schedule if you need it. }\end{array}$ \\
\hline Living social public lives & $\begin{array}{l}\text { Informed others of the sender's current activities, } \\
\text { intentions, likes and dislikes, creating opportunities } \\
\text { to explore shared interests, experiences, goals, } \\
\text { mindsets, and life dispositions/aspirations. }\end{array}$ & $\begin{array}{l}\text { Heading to [city name]: [URL to } \\
\text { map pinpointing current } \\
\text { location] }\end{array}$ \\
\hline $\begin{array}{l}\text { Digital identity and } \\
\text { impression management }\end{array}$ & $\begin{array}{l}\text { Drew attention to their work and professional } \\
\text { endeavours. }\end{array}$ & $\begin{array}{l}\text { My interview on [topic related to } \\
\text { professional interests]: [URL] }\end{array}$ \\
\hline Connecting and networking & $\begin{array}{l}\text { Sought to connect and network with other, while } \\
\text { also acting as 'connectors' between individuals. }\end{array}$ & $\begin{array}{l}\text { Visit colleague's new blog and } \\
\text { leave her a comment [URL] }\end{array}$ \\
\hline $\begin{array}{l}\text { Presence across multiple } \\
\text { online social networks }\end{array}$ & $\begin{array}{l}\text { Highlighted their participation in other online social } \\
\text { networks and alerted/directed others of activities } \\
\text { that occurred in other online spaces. }\end{array}$ & $\begin{array}{l}\text { I favorited a YouTube video: } \\
\text { [Video title] [URL] }\end{array}$ \\
\hline
\end{tabular}

institution names were omitted to add another level of anonymity. Finally, hashtags (i.e. the Twitter practice of adding the \# symbol in front of a keyword ${ }^{3}$ ) were edited or removed, again to preserve anonymity. A peer review of the revisions indicated that $97.2 \%$ of these changes left the meaning of the data unaltered. Discriminate cases were discussed and edited such that researchers reached $100 \%$ agreement that revised tweets maintained their original meaning. Findings are presented in detail below, and a summary is provided in Table 2 .

\section{Information, resource, and media sharing}

The practice of sharing information, media, and resources was the dominant activity of scholars' participation, coded as such in $39 \%$ of the data sample. Examples included the sharing of information ('[Speaker] is discussing education and technology at [institution name]: [URL]'), media ('Simulation of [an event] in a video game [URL]'), or news ('Celebrating YouTube's five year anniversary: [URL]'). Additionally, while participants shared items relevant to their professional endeavours (e.g. '[Website Name] is one good resource for open educational resources, @user' or 'This study examines how best to identify [social science topic]: [ULR]'), they also shared items relevant to their non-professional life ('Listening to these songs tonight: [URL to blog entry listing songs]'). At times, information sharing occurred while participants were at conferences (e.g. 'Watching the captivating [person name] deliver the keynote at [conference]!').

Participants used four approaches to share these items:

- Sharing with all of their followers (e.g. 'interesting book that discusses [economics concept]: [Book Name] [URL]').

- Sharing with all of their followers while bringing the item to the attention of specific individuals (e.g. 'This year's [Name] Announcement has the \#[TAG], @user').

- Sharing with all of their followers while at the same time bringing it to the attention of individuals or groups following a hashtag (e.g. 'An instructional guide of best practices in [Technology]: [URL] \#[Technology]').

- Forwarding information (e.g. 'RT @user: did you see the update on [topic] from yesterday? See [URL]'). Forwarding information on Twitter is referred to as ReTweeting. Messages are indicated as retweets by 
being prefaced by the letters RT, as in the example above. At times personal commentary was attached to forwarded messages as in the case of the comment that is italicized in the following message: 'Data needed for this claim. RT: @ user Increased social networking will democratize unequal gender participation'.

Finally, participants in this sample shared information relating to new technological tools or developments that they seemed to find interesting or worthwhile. For example, one participant noted that '[Recentlylaunched Role Playing Game] appears appealing: [URL]', while another shared a link to a video and commented on the appeal of the filming technique.

\section{Expanding learning opportunities beyond the confines of the classroom}

The scholars who were part of this study used the Twitter network as a way to make classroom activities/ information available to others and to provide opportunities for students to interact with individuals outside of the classroom. For instance, participants asked others to help their students with questions they had (e.g. 'My class needs your input on teen bullying. Please comment: [URL]') and shared and showcased student work (e.g. 'My students co-authored this remarkable article: [URL]'). Faculty appeared to be transparent about their classroom practices and used Twitter to draw attention to these practices. Persistent practices observed related to participants sharing classroom activities with others and directing others to Web-based artefacts being used in their classroom, developed for classroom assignments, or produced by the students. For instance, one participant noted that she was 'delighted with the contribution of @studentName who is my student: [Blog post Title and URL]' and in a follow-up tweet asked her followers to contribute their thoughts to the student's blog. Additional examples included:

- My slides for Tuesday's \& Thursday's teaching sessions in [class name]: [URL]

- My blog post with student-filmed video: [URL]

- [University Name] students' video explaining [topic]: [URL]

Finally, the data collected include examples of Twitter being used as a way for instructors to publicly direct their students to specific information relevant to class (e.g. 'EDUXXXX: see this great example of using video: [URL]'). In the instances where resources were shared with one's class, the standard practice was to attach a hashtag to the tweet (presumably, so that students could follow and attend to updates and conversations).

\section{Requesting assistance and offering suggestions}

Participants also utilized their Twitter network to intentionally enhance their own knowledge and practice. For instance, participants requested examples and resources that they could use in their teaching (e.g. 'Do you have any excellent examples of interactive whiteboard uses in education? I'm looking for examples for Thursday's class', and 'Can you point me to your favorite politicians' Facebook Pages that I can use in my course?'). In other instances, instructors sought recommendations and assistance that would enhance their skills and/or practice (e.g. 'How do you use [technology] in or out of the classroom? I want to learn from you, so please tell me about it' or '[Software] does not allow me to create an interactive image to publish on the Web. What software can do this?'). Finally, participants sought information relevant to their scholarship and research (e.g. 'I am writing a paper on [topic]. If you have knowledge of [topic] I would be grateful for your suggestions', and 'Does anyone have any article recommendations on the impact of Internet access on [population of interest]?'). While these inquiries can be described as requests for assistance, they also serve to inform others of an individual's teaching and research interests.

Providing assistance, feedback, and input to others is another characteristic of scholars' participation on Twitter. For instance, participants answered questions (e.g. 'Yes, @user. [School name] should add a class on [topic]' or '@user1@user2, here is the information on [topic]: [URL]'), and provided resources in response to such requests (e.g. 'This is an example of digital content creation: [URL], @user'). In other cases, participants directed users to examples and offered to provide further input if that was needed (e.g. 'Here is an example [URL] @user. I can also send my course schedule if you need it'), or voluntarily offered suggestions to colleagues: 'If you teach [topic], this might be valuable to your students: [URL]'. 


\section{Living social public lives}

Twitter is often dismissed as a platform of meaningless soliloquies and dull updates. For instance, Malesky and Peters (in press) note that "many Tweets contain relatively mundane status updates or information about the Tweeter' while Hough (2009, p. 411) notes that the service is '[o]ften ridiculed as a frothy time-waster'. The data analysed for this paper, however, indicate otherwise. Of the 4500 tweets analysed, $22.7 \%$ were responses to one or more individuals and $19.2 \%$ were contributions intended for individuals sharing a common interest (i.e. tweets tagged with a specific hashtag). Without exception, all participants shared updates pertinent to their day-to-day activities that may be construed as meaningless chatter. Nevertheless, such updates represent important personal and social commentary because they inform others of the sender's current activities, intentions, likes and dislikes, and life outside the profession. Rather than representing meaningless chatter, such updates may introduce opportunities to explore shared interests, experiences, goals, mindsets, and life dispositions/aspirations. Examples of such updates include the following:

- I am reading [title of a science fiction novel] tonight.

- I $\bullet$ [Song Title] by [Artist]: [URL to song]

- Here is my latest artwork: [URL]

- My son and I are really excited to see my parents tomorrow.

- [Husband's name] and I are celebrating our Xth anniversary today!

- mmmm earl grey tea

- Heading to [city name]: [URL to map pinpointing current location]

- Happy birthday @user

- We are watching [Movie Name] tonight.

\section{Digital identity and impression management}

The ability to create, manage, and traverse profiles on social networking sites has given rise to digital notions of self-presentation and impression formation. The topic of digital identity management has appeared prominently in the collected dataset, as participants used Twitter to draw attention to their work and professional endeavours:
- Mention of my presentation at [University Name]: [URL]

- Heading to [University Name] to give a talk to the [name] Group: [URL]

- Appreciative for the comments and the hundreds of views/day on this presentation: [URL].

In addition to sharing information regarding lectures and presentations, participants also shared links to interviews that they gave:

- In my interview with the editor of [name], I discuss [topic]: [URL]

- [URL]: My interview on [topic related to professional interests]

- Interview with [Periodical name]: [URL]

Tweets that highlight colleague achievements ('Enjoyed @user's response to [topic]: [URL]'), institutional events/successes ('Well done [Name] for accepting a position at [University and Department] [URL]'), and appreciation ('great colleagues@user1 @user2@user3 \#FF'4) can be seen as laudatory, but also as actions and information that manage impressions. Such 'public displays of connection' (Donath \& boyd 2004) validate status and connection identity.

Outside of their professional practice, participants also drew attention to their personal accomplishments. At the time of writing this paper, a current networked practice related to individuals snapping one photograph per day as a way to document their lives, enhance their photography skills, and learn about each other. For instance, when one participant draws attention to her accomplishments in relation to this practice, 'Shot and posted pictures every single day for \#SnapAPicToday. See them here: [URL]', not only is she sharing information related to her interests, but she is also highlighting personal characteristics such as tenacity and dedication.

\section{Connecting and networking}

While shared social experiences may allow serendipitous bond formation, the scholars in this study also sought to actively connect and network with others, while also acting as 'connectors' between people. For instance, one individual sought recommendations for one of their students, 'Do you have any connections to anyone at [company name] to introduce to a [content 
area] student?', while another user sought individuals interested in connecting with a beginning teacher. Others sought to make introductions by giving recommendations on who to follow (e.g. '[Topic professionals] should follow @user1 and @user2'), or by introducing users to their colleagues' work (e.g. 'Visit colleague's new blog and leave her a comment [URL]'). Finally, connections between scholars went beyond recommendations, suggestions, and short remarks. Evidence of participants connecting with others and engaging in discussion on serious topics was also present in the data set. For instance, two individuals engaged in a lengthy discussion on the impact of the economy on higher education institutions and two others debated on whether there is enough evidence to support a particular hypothesis regarding youth's use of media.

\section{Presence across multiple online social networks}

Across the data analysed, it became evident that scholars are present on a number of other social platforms. Participants highlighted their participation in other online social networks, directed others to information/media that they posted in other online spaces, and alerted others of activities that occurred in other spaces. For instance, users linked their social networking services and autoupdated their status with activities that occurred on other sites (e.g. 'I favorited a YouTube video: [Video title] [URL]'), or, directed followers to sites where further information could be found about their activities (e.g. 'New Blog Post: [Post Title] [URL]' or 'This is what I am reading: [Image of a book cover taken with a Smartphone and uploaded on an image sharing website]'). These activities indicate that participants maintained an active presence on social networking sites other than Twitter and sought to inform individuals of their activity on those spaces. These actions also indicate that participants sought to consolidate and reinforce their digital presence and share online activities that occurred across numerous spaces on Twitter.

\section{Implications and discussion}

The purpose of this paper was to understand scholars' online participation in networked spaces. In summary, the findings indicate that scholars' networked participation is a complex and multifaceted human activity where personal and professional identities blend, and where participatory digital practices meet individual reflections, fragmented updates, and social interaction. While a number of practices, such as resource sharing, are prevalent, scholars' participation on Twitter varies to accommodate multiple intended audiences, goals, and motivations.

This study provides naturalistic evidence that supports scholars' self-reported reasons for participating in online spaces, Web 2.0 applications and social media services. While scholars engage with their professional interests (cf. Meyer \& McNeal 2011), and share their research with others (Kjellberg 2010), the content of their tweets and their participation in multiple platforms indicate that they share diverse information that may be intended for multiple audiences. Martindale and Wiley (2005) have noted that academic bloggers may blog for multiple audiences, and this study provides evidence that scholars perform similar practices on Twitter. Nevertheless, it is important to highlight the fact that scholarly activity in networked spaces (e.g. posting draft thoughts regarding research endeavours and sharing student work) may be in conflict with current paradigms of scholarship (cf. Kirkup 2010). Such online practices may not be valued or understood by peers and academic institutions even though scholars themselves may have found scholarly value in participating in online spaces.

The findings also indicate that a number of scholars network in order to enhance their teaching by seeking input, sharing their work, engaging in conversation with others, and sharing student work. Through these actions participants seek enhanced learning opportunities for their students, and are willing to share teaching practices and artefacts outside of the classroom presumably because there are benefits that may be derived from their students having an expanded audience. These actions also indicate that participants capitalize on the affordances of the technology to bring together distributed expertise and introduce learners to individuals who are knowledgeable about a topic of study. Importantly, participants' Twitter followers were frequently directed to materials developed by the participants' students. This finding is important: While current literature suggests that incorporating online public writing (e.g. through student blogs) may yield positive outcomes (e.g. deeper reflection and more nuanced reading and writing) due to the presence of a real or assumed authentic audience (e.g. Martindale \& Wiley 2005; Ellison \& Wu 2008), 
this study's participants took an active role in introducing their students' writings to authentic audiences, encouraging participation, and requesting from students and classroom outsiders to engage in conversations with each other. We see here a new role for the instructor as an active network participant who connects students with his/her professional community.

While technological know-how appears to be important in enabling participants to introduce their students to online networks and virtual communities, the fact that Twitter has been used for this purpose is worthy of discussion. Even though social networking technologies in general were developed for purposes unrelated to education, they have been co-opted and repurposed by scholars, in part, to satisfy educational and scholarly pursuits. Thus, scholars have capitalized on the ease with which they can connect with others, traverse networks and communities of interest, and engage in conversations, in order to further their work. Nevertheless, tools such as Twitter are not neutral. In fact, they have intended uses, purposes, and practices, which, as a result of their adoption in scholars' life, influence the way academics engage in educational practices through these tools. For instance, the ease with which individuals can follow and remain updated on the activities, thoughts, resources, and work of individuals from disciplines outside of their own, enables increased awareness of others' work, possibly aiding multidisciplinary thinking or introduction to ideas outside of their own domain.

The reasons that scholars co-opt online social networks (e.g. Twitter) and online scholarly networks (e.g. Zotero, Mendeley, and Academia.edu) for educational and scholarly endeavours are complex, but seem to point to an increasing desire for more social scholarly pursuits and identities. The activities identified above paint these scholars as individuals who take on public intellectual roles and willingly and knowingly share information about themselves and their practice. Within this discussion, three points are worth considering:

- The type of public intellectual observed in this study is one who shares both professional and personal information. While the literature reviewed above has indicated that scholars desire to share their professional work with niche audiences (e.g. other researchers or practitioners), this research has shown that scholars also share details from their private lives. Taken literally and out of context, scholars' microblogging updates may appear to have no real function, but seemingly unimportant tweets serve significant social purposes. Non-scholarly social interaction is "essential to forging bonds, affirming relationships, displaying bonds, and asserting and learning about hierarchies and alliances' (cf. Tufekci, 2008, p. 546), leading to positive scholarly impacts (e.g. learning that a colleague enjoys the same hobby as you do, might be the tidbit of knowledge necessary to commence a conversation leading to future scholarly collaboration). On the other hand, however, knowledge gained from nonscholarly social interaction may alienate colleagues and hinder relationship building, especially given recent evidence that suggests that some faculty believe that having accounts on SNS constitutes inappropriate faculty behaviour (Malesky \& Peters, in press).

- The purposes of information sharing and the goals it fulfils. Are scholars altruistically sharing information for the benefit of the community in which they belong? Or, is information sharing a self-serving activity? Are scholars sharing information in order to assist the profession grow intellectually, or are they attempting to develop a 'brand' around themselves? To what extent are scholars' impression management activities (as signified by such things as the content of their tweets or references to other individuals in the profession) aimed at presenting an idealized scholar, a projected self to audiences (cf. Goffman 1959)? Scholars' reasons for sharing matter because an understanding of these reasons will allow us to gain a better sense of how and why Twitter and other social networks are used in the ways that they are. Such an understanding aligns with recent calls for educational technology research to investigate the social, political, cultural, and economic factors that influence technology use (Selwyn 2010).

- The question of causality with respect to technology and scholars' practices. Is Twitter fostering more social opportunities and community-oriented approaches to education and scholarly participation? Or, do the individuals who espouse these kinds of beliefs happen to make use of Twitter for scholarly pursuits? The co-opting argument above lends support to the latter explanation. A definitive answer, however, is not available. What becomes evidently clear is that scholarly participation in online spaces is an emerging practice and, as such, remains fairly elusive and in need of further inquiry. 
Finally, variation in how Twitter is used among scholars points to the differential value individual scholars perceive Twitter to provide to their practice. Even though scholars' practices described above capture the overall activity of these participants, note that not all participants enact all the practices described. For instance, one individual in the sample broadcasted professional information and did not share any personal information or requested/provided input to others. Conversely, another user's tweets indicate that more than $63 \%$ of his participation represented one-to-one interaction with others. Future research should focus on understanding such variability and investigating how scholars' intentions match social network use.

\section{Limitations}

It is important to note that the data presented in this paper represent a unique sample of individuals who may be considered to be early adopters, partly as a result of their consistent participation on Twitter, and partly because of their relatively large following. While this paper provides an understanding of how scholars may use Twitter for professional practices, the selected sample's use of Twitter may differ from the average scholar's use of Twitter. Moreover, scholar participation is presented in an aggregate form without differentiating between participants' professional roles (e.g. with regard to teaching vis-à-vis research) or personality traits, such as extraversion (cf. Correa et al. 2010), that might have influenced SNS use. Importantly, the study's gender mix (38 men, 7 women) might have also influenced the results. For instance, Cotten and Jelenewicz (2006) have shown that men and women differ in the ways and regularity with which they use the Internet, and Sax et al. (2001) have shown that technological preparedness varies with gender. Future studies should attempt to investigate a wider range of scholars and the factors mediating their participation (e.g. those who are less followed; those who are at the beginning stages of utilizing online social spaces for professional pursuits; those within a specific discipline; those whose professional roles with respect to teaching vs. research vary; or across gender lines) in order to examine whether varied scholarly populations use Twitter in different ways. Such research will clarify the extent to which the results reported here are observable in diverse scholarly populations and help us understand how differing conditions influence scholars' online practices.

\section{Conclusion}

In this paper, I presented data examining scholars' practices on Twitter. While this research provides an important step in understanding social network participation for scholarly purposes, numerous issues deem further investigation including the development of academics' digital identities, the role of scholars in networked spaces, and their motivations for participation.

Participatory technologies are repurposed into scholarly networks where scholars can share resources, support each other in professional pursuits, and engage in the type of informal interactions usually reserved for the water cooler. When Kumashiro et al. (2005) lamented scholarly activity as one that lacks ongoing participation, support, and conversation, they envisioned a healthy community of scholars, which would embrace and support scholarly growth and reflection. The participation observed on Twitter presents opportunities for such a vision, but it is still too early to tout online social spaces as closely knit scholarly communities. The snapshot presented in this paper is promising but the emergent nature of online social spaces and online scholarship requires further investigation.

\section{Acknowledgements}

The author would like to thank two anonymous reviewers for their feedback, and Cesar Navarrete, Greg Russell, Jaejin Lee, Nikos Aspiotis, and Marilena Aspioti for their assistance with various portions of this manuscript.

\section{Notes}

${ }^{1}$ Any reference to scholarship and scholarly practice should be understood to
include both teaching and research activities (Hutchings \& Shulman 1999).
${ }^{2}$ The RPI is a worldwide initiative to classify universities according to research
output http://www.highimpactuniversities.com/rpi.html
${ }^{3}$ The following is a fictitious tweet that illustrates this practice (\#virtualk12 is
the hashtag): 'What are your thoughts on the increasing prevalence of online
learning in K-12 education? \#virtualk12'.
${ }^{4} \#$ FF or \#FollowFriday is the Twitter practice of recommending users to others
through posting a series of usernames and the \#FF or \#FollowFriday hashtags.

References

Ajjan H. \& Hartshorne R. (2008) Investigating faculty decisions to adopt Web 2.0 technologies: theory and empirical tests. The Internet and Higher Education 11, 71-80. 
boyd D. \& Ellison N. (2007) Social network sites: definition, history, and scholarship. Journal of Computer-Mediated Communication 13, 210-230.

Coddington R. (2010) Professors' Use of Technology in Teaching. The Chronicle of Higher Education. Available at: http://chronicle.com/article/article-content/123682 (last accessed 5 August 2010).

Conole G. (2011) Book: Designing for Learning in An Open World. Available at: http://cloudworks.ac.uk/cloudscape/ view/2155 (last accessed 12 April 2011).

Correa T., Amber H. \& Homero Z. (2010) Who interacts on the Web?: the intersection of users' personality and social media use. Computers in Human Behavior 26, 247-253.

Cotten S. \& Jelenewicz S. (2006) A disappearing digital divide among college students? Social Sciences Computer Review 24, 497-506.

Crawford K. (2009) Following you: Disciplines of listening in social media. Continuum: Journal of Media \& Cultural Studies 23, 525-535.

Donath J. \& boyd D. (2004) Public displays of connection. BT Technology Journal 22, 71-82.

Dron J. \& Anderson T. (2009) How the crowd can teach. In Handbook of Research on Social Software and Developing Community Ontologies (eds S. Hatzipanagos \& S. Warburton), pp. 1-17. IGI Global Information Science, Hershey, PA.

Dunlap J. \& Lowenthal P. (2009) Horton hears a tweet. EDUCAUSE Quarterly 32, 1-10.

Ebner M., Lienhardt C., Rohs M. \& Meyer I. (2010) Microblogs in higher education - a chance to facilitate informal and process-oriented learning? Computers and Education 55, 92-100.

Ellison N.B. \& Wu Y. (2008) Blogging in the classroom: a preliminary exploration of student attitudes and impact on comprehension. Journal of Educational Multimedia and Hypermedia 17, 99-122.

Ellison N.B., Steinfield C. \& Lampe C. (2007) The benefits of Facebook 'Friends': social capital and college students' use of online social network sites. Journal of ComputerMediated Communication 12, 1143-1168.

Faculty Focus (2010) Twitter in Higher Education 2010: Usage Habits and Trends of Today's College Faculty. Available at: http://www.facultyfocus.com/free-reports/ twitter-in-higher-education-2010-usage-habits-andtrends-of-todays-college-faculty/ (last accessed 17 December 2010).

Giorgi A. (1997) The theory, practice, and evaluation of the phenomenological method as a qualitative research procedure. Journal of Phenomenological Psychology 28, 235260.

Glaser B.G. \& Strauss A.L. (1967) The Discovery of Grounded Theory. Aldine Publishing, Chicago, IL.
Goffman E. (1959) The Presentation of Self in Everyday Life. Doubleday, Garden City, NY.

Gowers T. \& Nielsen M. (2009) Massively collaborative mathematics. Nature 461, 879-881.

Greenhow C. (2009) Social scholarship: applying social networking technologies to research practices. Knowledge Quest 37, 42-47.

Greenhow C. (2011) Online social networking and learning. International Journal of Cyber Behavior, Psychology and Learning 1, 36-50.

Greenhow C. \& Robelia E. (2009) Old communication, new literacies: social network sites as social learning resources. Journal of Computer-Mediated Communication 14, 1130 1161.

Greenhow C., Robelia B. \& Hughes J. (2009) Learning, teaching, and scholarship in a digital age: Web 2.0 and classroom research: what path should we take now? Educational Researcher 38, 233-245.

Hemmi A., Bayne S. \& Land R. (2009) The appropriation and repurposing of social technologies in higher education. Journal of Computer Assisted Learning 25, 19-30.

Hew K.F. (2011) Students' and teachers' use of Facebook. Computers in Human Behavior 27, 662-676.

Hough M.G. (2009) Keeping it to ourselves: technology, privacy, and the loss of reserve. Technology in Society 31, 406-413.

Huberman B., Romero D. \& Wu F. (2009) Social networks that matter: Twitter under the microscope. First Monday. Available at http://firstmonday.org/htbin/cgiwrap/bin/ojs/ index.php/fm/article/view/2317/2063 (last accessed 30 August 2011).

Hutchings P. \& Shulman L. (1999) The scholarship of teaching: new elaborations, new developments. Change 31, $10-15$.

Ito M., Baumer S., Bittanti M., boyd D., Cody R., HerrStephenson B., Horst H., Lange P., Mahendran D., Martínez K., Pascoe C.J., Perkel D., Robinson L., Sims C. \& Lisa T. (2009) Hanging Out, Messing Around, and Geeking Out. Digital Media. MIT Press, Cambridge, MA.

Java A., Song X., Finin T. \& Tseng B. (2007) Why we twitter: understanding micro-blogging usage and communities. Paper presented at the Proceedings of the 9th WebKDD and 1st SNA-KDD 2007 Workshop on Web Mining and Social Network Analysis.

Junco R., Heiberger G. \& Loken E. (2011) The effect of Twitter on college student engagement and grades. Journal of Computer Assisted Learning 27, 119-132.

Katz R. (2010) Scholars, scholarship, and the scholarly enterprise in the digital age. EDUCAUSE Review 45, 44-56.

Kirkup G. (2010) Academic blogging: academic practice and academic identity. London Review of Education 8, 75-84. 
Kirschner P. \& Karpinski A. (2010) Facebook and academic performance. Computers in Human Behavior 26, 12371245.

Kjellberg S. (2010) I am a blogging researcher: motivations for blogging in a scholarly context. First Monday. Available at http://firstmonday.org/htbin/cgiwrap/bin/ojs/index. php/fm/article/view/2962/2580 (last accessed 30 August 2011).

Kumashiro K.K. (2005) Thinking collaboratively about the peer-review process for journal-article publication. Harvard Educational Review 75, 257-285.

Lave J. \& Wenger E. (1991) Situated Learning: Legitimate Peripheral Participation. Cambridge University Press, Cambridge, UK.

Luckin R., Clark W., Graber R., Logan K., Mee A. \& Oliver M. (2009) Do Web 2.0 tools really open the door to learning? Practices, perceptions and profiles of 11-16-yearold students. Learning, Media and Technology 34, 87-104.

Malesky L.A. \& Peters C. (in press). Defining appropriate professional behavior for faculty and university students on social networking websites. Higher Education. doi:10.1007/s10734-011-9451-x.

Martindale T. \& Wiley D.A. (2005) Using weblogs in scholarship and teaching. TechTrends 49, 55-61.

Merriam S. (1995) What can you tell from an $\mathrm{N}$ of 1 ?: issues of validity and reliability in qualitative research. PAACE Journal of Lifelong Learning 4, 51-60.

Meyer K.A. (2010) A study of online discourse at The Chronicle of Higher Education. Innovative Higher Education 35, 1-17.

Meyer K.A. \& McNeal L. (2011) Academics online: their interests and foibles. The Internet and Higher Education 14, 113-120.

Moran M., Seaman J. \& Tinti-Kane H. (2011) Teaching, Learning, and Sharing: How Today's Higher Education Faculty Use Social Media for Work and for Play. Pearson Learning Solutions. Available at: http://tinyurl.com/ pearsonstudy (last accessed 30 May 2011).

Oblinger D.G. (2010) From the campus to the future. $E D U$ CAUSE Review 45, 42-52.

Oulasvirta A., Lehtonen E., Kurvinen E. \& Raento M. (2009) Making the ordinary visible in microblogs. Personal and Ubiquitous Computing 14, 237-249.

Pasek J., More E. \& Hargittai E. (2009) Facebook and academic performance: Reconciling a media sensation with data. First Monday. Available at http://firstmonday.org/ htbin/cgiwrap/bin/ojs/index.php/fm/article/viewArticle/ 2498/2181 (last accessed 31 August 2011).

Roblyer M.D., McDaniel M., Webb M., Herman J. \& Witty J.V. (2010) Findings on Facebook in higher education: a comparison of college faculty and student uses and perceptions of social networking sites. The Internet and Higher Education 13, 134-140.

Sax L., Ceja M. \& Teranishi R. (2001) Technological preparedness among entering freshmen: the role of race, class, and gender. Journal of Educational Computing Research 24, 363-383.

Selwyn N. (2009) Faceworking: exploring students' education-related use of 'Facebook'. Learning, Media and Technology 34, 157-174.

Selwyn N. (2010) Looking beyond learning: notes towards the critical study of educational technology. Journal of Computer Assisted Learning 26, 65-73.

Strauss A.L. \& Corbin J. (1998) Basics of Qualitative Research: Techniques and Procedures for Developing Grounded Theory. SAGE Publications, London.

Suler J. (2004) The online disinhibition effect. CyberPsychology and Behavior 7, 321-326.

Tufekci Z. (2008) Grooming, Gossip, Facebook and MySpace. Information. Communication and Society 11, 544-564.

Valenzuela S., Park N. \& Kee K.F. (2009) Is there social capital in a social network site?: Facebook use and college students' life satisfaction, trust, and participation. Journal of Computer-Mediated Communication 14, 875901.

Veletsianos G., ed (2010) A definition of emerging technologies for education. In Emerging Technologies in Distance Education, pp. 3-22. Athabasca University Press, Edmonton, AB.

Veletsianos G. \& Kimmons R. (2011a) Networked Participatory Scholarship: Emergent Techno-Cultural Pressures Toward Open and Digital Scholarship in Online Networks. Manuscript submitted for publication.

Veletsianos G. \& Kimmons R. (2011b) Scholars and Faculty Members Lived Experiences in Online Social Networks. Manuscript submitted for publication.

Veletsianos G. \& Navarrete C. (2011) Online Social Networks as Formal Learning Environments: Learner Experiences and Activities. Manuscript submitted for publication.

Walker J. (2006) Blogging from inside the Ivory Tower. In Uses of Blogs (eds A. Bruns \& J. Jacobs), pp. 127-138. Peter Lang, New York, NY.

Wenger E. (1998) Communities of Practice. Learning, Meaning and Identity. Cambridge University Press, Cambridge, UK.

White D., Manton M. \& Le Cornu A. (2009) Isthmus: Headline Findings Report. Joint Information Systems Committee. Available at: http://isthmus.conted.ox.ac. uk/raw-attachment/wiki/ProjectDocumentation/ IsthmusHeadlines.doc (last accessed 11 July 2011). 